\title{
ENERGY EXCHANGE AND ITS INFLUENCE FACTORS ON MOUNTAIN GLACIERS IN WEST CHINA
}

\author{
by
}

\author{
BaI ZHONGYUAN AND YU XINZHI
}

Lanzhou Institute of Glaciology and Cryopedology, Academia Sinica, Lanzhou, Gansu, People's Republic of China

\begin{abstract}
Heat balance studies were carried out during summer ablation periods $1960-1983$ by the glacial investigation team of the Chinese Academy of Sciences. The effect of energy exchange on development of mountain glaciers was determined, based on the observation of heat exchange over the glacial surface of various mountainous regions. Relationships between energy transfer and climatic parameters under different climatic regimes and landform conditions are analyzed in detail. It was found that the most important heat source for snow-ice melting is radiation, a contribution amounting to between $59.0 \%$ and $92.1 \%$ of the total. Sensible heat contributed $8-36 \%$. The sensible heat flux depends on the bulk transfer coefficient and the glacier cooling effect. The mean value is about 16.3 Ly/day.K. With the decrease of sea influence, altitude of the snow-line is elevated, aridity of glacier climate increases, evaporation increases gradually and melting decreases, providing conditions for glacial nourishment. When the glacier is covered with a debris layer, the glacier heat balance in continental regions is altered. Finally, the authors' investigation on the glacier No 1 , at the headwater of Urumqi river, shows that differences in structure of glacier heat balance are mainly the result of the influence of the topography and albedo on net radiation. Finally, diagrams of distribution of net radiation in space and time are presented.
\end{abstract}

\section{INTRODUCTION}

Mountain glaciers situated at different latitudes and in various climatic regions of West China have different snow-line elevations and development conditions (Shi Yafeng 1980). Such basic features are associated with solar radiation and heat exchange processes, so that the studies of these processes are useful for better knowledge of the hydrothermal condition of glacial development.

Investigations of glacial heat balance in China began in 1958 during the practical experimental period for the artificial dusting of glaciers in the Qilian Mountains. Two stations were established at Mt Daxue and Mt Tulai to study radiation and heat exchange (Tang Maocang and Yang Songxi, unpublished report 1963).

From 1960 to 1983 a systematic observation of glacial surface radiation and heat exchange was carried out in nine glacierized regions by the Investigation Team for the Utilization of Snow and Ice on High Mountains and the multi-disciplinary expedition. These observed sites were situated in various climatic zones, and glaciers are of the continental type.

In order to better understand the characteristics of the ablation process of snow and ice, the relationship between energy transfer, climatic parameters and topography on radiation balance is needed. Based on analysis and computation during $1962-63$ on Glacier No 1 at the headwater of Urumqi River, cooperative studies between Chinese and Japanese scientists were begun during mid-summer 1983, on the glacierized region of Urumqi River headwater, under the direction of Professor Shi Yafeng and Professor Higuchi. The present article is a preliminary report on the major results of these investigations.

\section{BASIC REGIME OF HEAT EXCHANGE ON MOUNTAIN GLACIERS}

Observed and computed data from surfaces of eight glaciers (No 1 Glacier of Urumqi River in the Tianshan Mountains, No 4 Glacier of Shuiguan River and No 1 Glacier of Yanglong River in the Qilian Mountains; Qieerganbulake Glacier in Mt Muztagata; West Qiongtailan Glacier in Mt Tuomor; No 3 Glacier of Guxiang in Nyainqentanglha Range, Rongbuk Glacier in Mt Qomolangma, and Batura Glacier in Karakoram Mountains), showed relationships between different aspects of heat balance in the various glacier regions. Analysis and computation show that:

a) In most moutain glaciers in Western China, the most important source is radiation, amounting to between $59.0 \%$ and $92.1 \%$ of the total heat budget. A less important heat source is sensible heat, accounting for about $8-36 \%$ (from turbulent heat transfer between the ice-snow surface and the air layer near the surface). Surface ablation of a bare glacier consumes more than $80 \%$ of the heat output. The percentage of heat consumed from melting ice-snow ranges from $56.4 \%$ to $97.0 \%$.

b) Composition of heat budgets has an obvious regional regularity. In the western flank of Qinghai-Xizang plateau, the heat income of radiation balance always increases with decreasing latitude and increasing altitude. However, on the eastern flank it decreases owing to influences of moist air from southeastern and southwestern monsoons. From Glacier No 4 of Shuiguan River on the northeastern flank to Glacier No 3 of Guxiang on the southeastern flank, sensible heat input increases from $69.7 \mathrm{Ly} /$ day to $128.8 \mathrm{Ly} / \mathrm{day}$, and the percentage of heat supply ranges from $14.3 \%$ to $26.4 \%$ respectively (Wang Zhonglong and others 1982). The minimum value of sensible heat occurs in Qieerganbulake Glacier of Mt Muztagata, an arid mountainous region where the daily amount is only $22.6 \mathrm{Ly} /$ day or $7.9 \%$ (Zeng Minxuan and others 1966). Intensive latent heat exists only in Glacier No 3 of Guxiang, due to warm moist air, and reaches a maximum value of $51.5 \mathrm{Ly} /$ day. In others condensation is less. Aridity of glacier climates increases with elevation, and evaporation increases gradually as melting decreases. In the Qieerganbulake Glacier, latent heat of evaporation accounts for about $118.8 \mathrm{Ly} /$ day or $41.5 \%$ of the total heat output. The distribution of evaporation on glaciers depends on latitude and elevation, but on the Qinghai-Xizang Plateau evaporation increases unevenly from around the mountains toward the interior of the Plateau. High evaporation is an important component of mass balance and provides conditions for glacial nourishment in the zones of larger incoming radiation, running from the southern flank to the western flank of Qinghai-Xizang Plateau (Table 1).

\section{THE MAIN FACTORS AFFECTING ENERGY EXCHANGE ON MOUNTAIN GLACIERS}

Differences in radiation balance and heat exchange mainly result from differences in albedo, topographic conditions and local climate. These include the direction and slope of the glacier, and screening effect of the mountains, as well as the extent of superglacial debris. The most important points can be summarized as follows: 
TABLE 1. CONSTITUTION OF HEAT BALANCE IN VARIOUS GLACIERIZED REGIONS DURING THE ABLATION PERIOD.

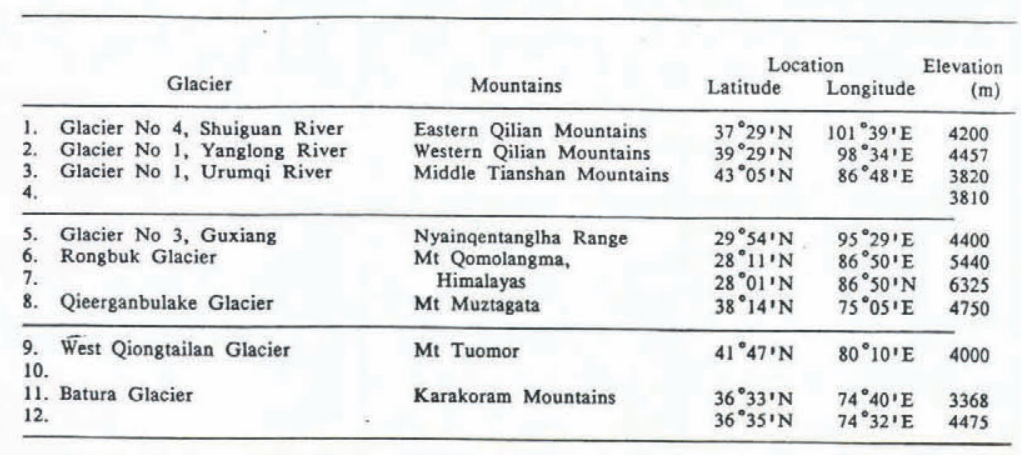

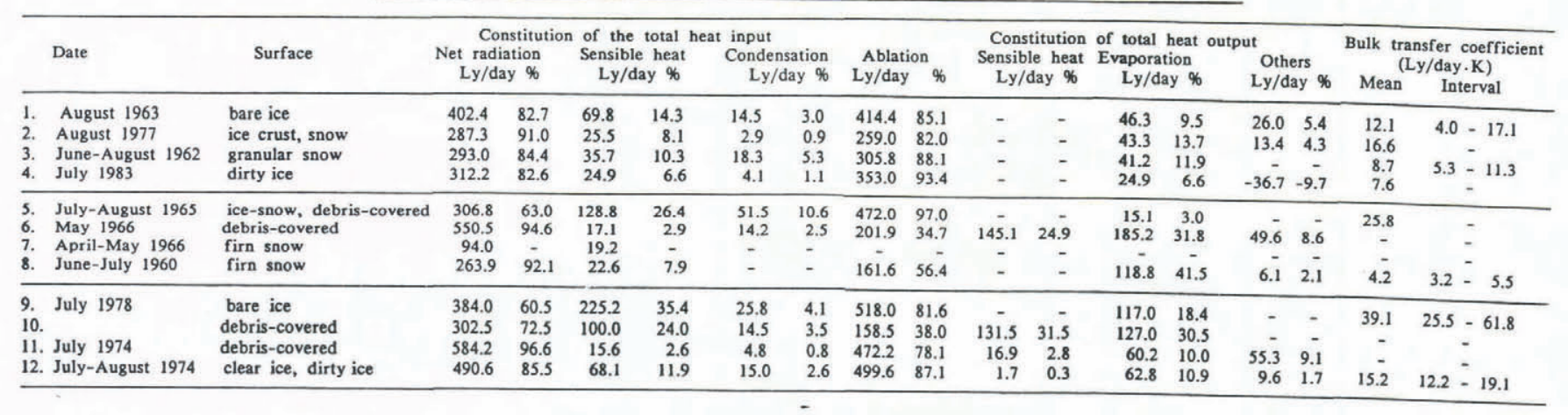

The effect of albedo on energy exchange

According to field observed data in the investigated region, albedo varied greatly between 0.81 and 0.12 , depending on surface conditions. For example, albedo on dry snow averages $0.81(0.70$ to 0.98$)$, on clean firn 0.60 (0.51 to 0.69$)$, on old snow $0.46(0.43$ to 0.50$)$, on clear ice 0.38 ( 0.34 to 0.42$)$, on slightly dirty ice 0.29 ( 0.26 to 0.33$)$, on dirty ice $0.21(0.15$ to 0.25$)$ and on debris-covered ice surfaces only $0.12(0.10$ to 0.14$)$. Based on computation of the Shuiguan River Glacier, the Urumqi River Glacier and the Rongbuk Glacier, on clear days with almost equal amount of global radiation, the absorbed radiation is about 3 times less, and the decrease of net radiation is over 300 Ly/day (Kou Youguan and others 1982a). Albedo transformation from ablational area to accumulational area of ten causes net annual radiation to change from a positive to a negative value, and provides conditions for ice and snow storage. According to measured data along the east branch glacier on Glacier No 1, Urumqi River headwater, the spatial distribution map of albedo obviously reflects the relationship between albedo and altitude. Except for energy losses due to the exposure and screening effect of the mountains, the reduction in net radiation caused by the albedo change is most important for glacial ablation and heat balance in summer. Calculations show a reduction of absorbed radiation by about 2.43 times, and decrease of net radiation of over $340 \mathrm{Ly} / \mathrm{day}$, when albedo decreases from 0.710 to 0.250 at a solar declination of $20^{\circ}$ (from June to August). But together these three components reduce the above energy by about 3.11 times and $303.3 \mathrm{Ly} /$ day respectively in the same conditions.

The effect of glacial surface regime on heat exchange

Observation in various glacierized regions of West China shows that differences in regime of glacial surface cause differences in thermal stratification near the glacial surface. Variations in debris area and dirt content also affect thermal stratification and the surface roughness parameter. In the case of a melting ice-snow surface, the sensible heat gradually decreases as the stability increases. Under the influence of glacier wind and local winds, as well as advection from lateral moraine and slope, the heat transfer process is highly variable, particularly in view of its dependence on glacier temperature, ie temperature jump $\mathrm{Dj}$. The sensible heat flux increases with the $\mathrm{Dj}$ value, since the bulk transfer coefficient of thermal air bulk over the glacier is closely related to the $\mathrm{Dj}$ value. Compuations have shown that the $\mathrm{Dj}$ value increases from 0.7 to 3.5 , the bulk transfer coefficient from 7.6 Ly/day.K to 39.1 Ly/day.K. under the same local wind conditions.

But, under stable thermal stratification conditions the transfer coefficient and friction velocity $u_{*}$ have a linear relationship with the $\Delta t_{2.0-0.5}$ value (Bai Zhongyuan, unpublished report 1963). Calculated results show transfer coefficients of $0.687 \mathrm{gr} / \mathrm{cm} . \mathrm{sec}, 0.396 \mathrm{gr} / \mathrm{cm} . \mathrm{sec}, 0.373$ $\mathrm{gr} / \mathrm{cm} . \mathrm{sec}$, and $0.377 \mathrm{gr} / \mathrm{cm} . \mathrm{sec}$ respectively on the Hornkees Glacier (Zillertaler Alps), No 9 Glacier of Dadonggou, Liushugou Glacier (Qilian Mountains), and Glacier No 1, Urumqi River headwater. This shows the diversity of the regime of heat transfer by turbulence under the influence of mountain valley and glacial winds.

However, when the glacier is covered with a debris layer, the heat budget is changed. Of the total heat income, the percentage of radiation balance contribution increases to $89.2 \%$ and the contribution of sensible heat and latent heat decreases to $9.1 \%$ and $1.7 \%$ respectively. Of the heat output, the heat consumed in the ablation decreases to $58 \%$ (from $34.7 \%$ to $78.1 \%$ ), the heat exchange in the debris layer may increase to as much as $8.6-9.1 \%$, the rest being consumed in evaporation and in the diffusion into the adjacent lower layer of air by turbulent heat exchange.

\section{The effects of topographic condition on radiation and heat balance}

From $52 \%$ to $78 \%$ of the glaciers in West China are found on north slopes (Liu Guangyuan 1978). This factor shows the close relationship between energy, weather regimes and topographic features.

In order to specify this relationship, differences in solar radiation due to the influence of direction and angle of the slopes were calculated for the East branch glacier of Glacier No 1 and a glacier-free cirque at the at the headwater of Urumqi River. The method developed by Wendler (Wendler and others 1974) was used (Bai Zhongyuan and others, unpublished 1984). Statistics of slope direction in glacier and glacier-free cirque show that most slope northward and southward respectively (Figure 1). Based on calculated data of the different directions and inclination of glacier and cirque, and the slope factor of solar radiation, results show that reductions in solar 


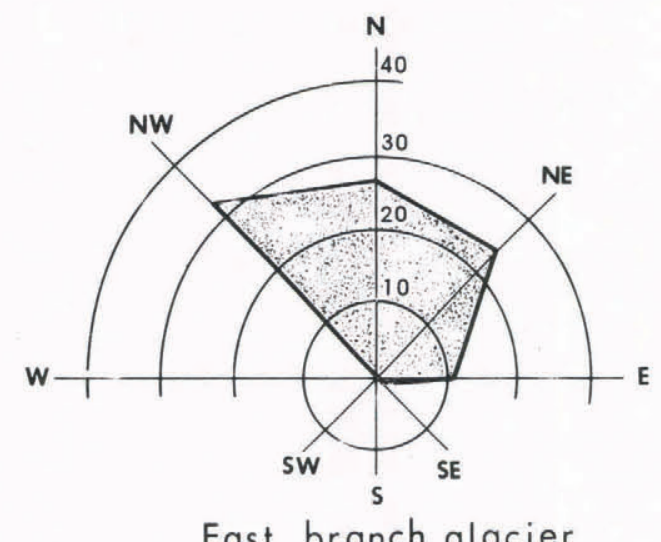

(a)

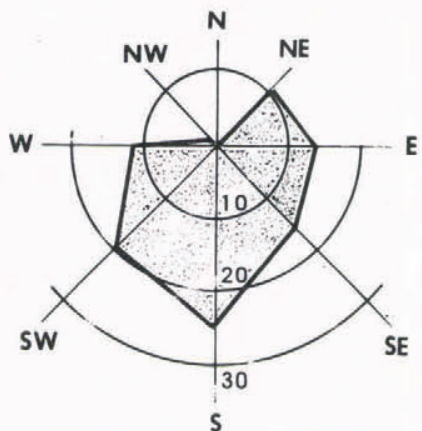

Glacier-free cirque

( b )

Fig.1. Frequency distributions of the slope direction of the East-branch glacier (a) and the glacier-free cirque (b), at headwater of Ürümqi River.

radiation owing to northerly or southerly exposure are small in July (intensive ablation period), about $7.8 \%$ and $4.4 \%$ respectively. But in the period of shorter solar path (for a solar declination of $-10^{\circ}$ ) the difference becomes more important. In the glacier area, the loss in radiation is $18 \%$ at the equinox, and even reaches $29.4 \%$ in early winter (solar declination is $-10^{\circ}$ ). But in the glacier-free area during the same period, energy received on the southerly slope is about $1.2-1.5$ times more than on a flat surface, so that there is no solar radiation energy deficit, and the loss is negative; ie the received energy at southerly exposure is about $9.5 \%$, and $16.1 \%$ more than on a flat surface.

Duration of sunshine is greatly influenced by topography, since the shadowing effect of the surrounding mountains is important. According to the computed data of the sunrise and sunset at various solar declinations at 29 points (23 points in glacier area and 6 points in glacier-free area, as shown in Figure 2), the losses in duration and energy were calculated by the sime-experience formula given by Kou Yanguan and others (1982b). These results are given in Table 2. Meanwhile, the energy received on two areas for different solar delineations under influences of exposure and screening are shown in Table 3 . On the basis of the calculated results for July (the middle of the ablation period), the distribution charts of mean daily value of insolation duration ( $\mathrm{S}_{\mathrm{t}}$ per hour), of the global radiation on the East-branch glacier $\left(Q_{\alpha \beta}\right)$ under clear weather was plotted (Figure 3). By knowing the spatial distribution of the above two factors, the corresponding distribution of the mean monthly albedo $\left(A_{k}\right)$ and mean daily value of net radiation on the physical surface $\left(B_{\alpha \beta}\right)$ could be calculated from the sime-experience formula and albedo observations on the glacier. Based on observed data in four glacierized regions situated in different climatic regions (ie No 1 Glacier of Urumqi River, No 4 Glacier of Shuiguan River,
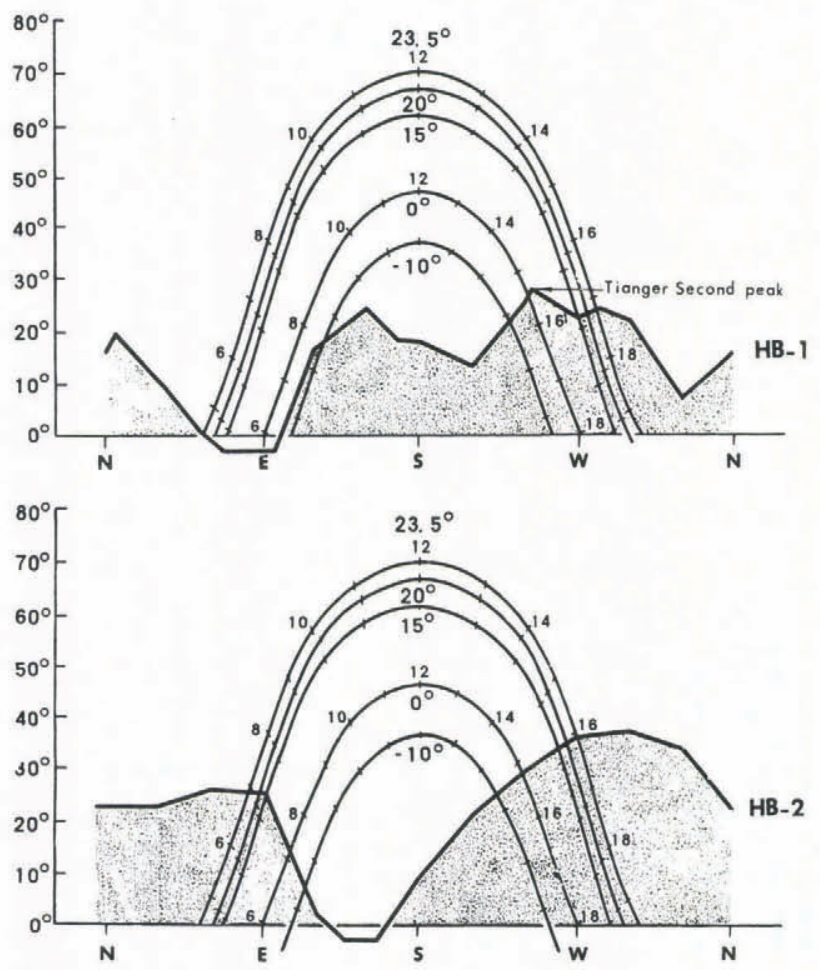

Fig.2. The screening of the mountains for the HB-1 and HB-2 sites, and five sun paths for the solar declinations of $23.3^{\circ}, 20^{\circ}, 15^{\circ}, 0^{\circ}$ and $-10^{\circ}$.

TABLE 2. LOSS IN DURATION AND ENERGY FOR THE WHOLE EAST BRANCH GLACIER AND GLACIER-FREE CIRQUE OWING TO THE SCREENING EFFECTS OF THE SURROUNDING MOUNTAINS FOR DIFFERENT SOLAR DECLINATIONS.

\begin{tabular}{lcccc}
\hline & Loss in duration (\%) & \multicolumn{2}{c}{ Loss in energy (\%) } \\
\hline $\begin{array}{l}\text { Solar dec- } \\
\text { lination } \\
\text { (Degree) }\end{array}$ & $\begin{array}{c}\text { East branch } \\
\text { glacier }\end{array}$ & $\begin{array}{c}\text { Glacier-free } \\
\text { cirque }\end{array}$ & $\begin{array}{c}\text { East branch } \\
\text { glacier }\end{array}$ & $\begin{array}{c}\text { Glacier-free } \\
\text { cirque }\end{array}$ \\
& & & & \\
23.5 & 19.2 & 36.2 & 21.9 & 28.8 \\
20 & 21.3 & 36.0 & 22.8 & 28.8 \\
15 & 24.0 & 35.2 & 23.9 & 28.4 \\
0 & 32.1 & 30.4 & 27.2 & 26.5 \\
-10 & 37.4 & 28.8 & 29.3 & 25.8 \\
\hline
\end{tabular}

TABLE 3. ENERGY RECEIVED ON EAST BRANCH GLACIER AND GLACIER-FREE CIRQUE FOR DIFFERENT SOLAR DECLINATIONS (ON THE ASSUMPTION THAT THE INCOMING SOLAR RADIATION FOR HORIZONTAL UNSCREENED SURFACE IS $100 \%$ ).

\begin{tabular}{ccccccr}
\hline $\begin{array}{c}\text { Solar de- } \\
\text { clination } \\
(\mathrm{deg})\end{array}$ & $\begin{array}{c}\text { Exposure } \\
\text { (\%) }\end{array}$ & $\begin{array}{c}\text { Screening } \\
(\%)\end{array}$ & $\begin{array}{c}\text { Total } \\
(\%)\end{array}$ & $\begin{array}{c}\text { Exposure } \\
(\%)\end{array}$ & $\begin{array}{c}\text { Screening } \\
(\%)\end{array}$ & $\begin{array}{r}\text { Total } \\
(\%)\end{array}$ \\
\hline 23.5 & 94.7 & 78.1 & 74.0 & 93.3 & 71.2 & 66.4 \\
20 & 92.2 & 77.2 & 71.2 & 95.6 & 71.2 & 68.1 \\
15 & 90.0 & 76.1 & 68.5 & 98.5 & 71.6 & 70.5 \\
0 & 82.0 & 72.8 & 59.7 & 109.5 & 73.5 & 80.5 \\
-10 & 70.6 & 70.7 & 49.9 & 116.1 & 74.2 & 86.1 \\
\hline
\end{tabular}




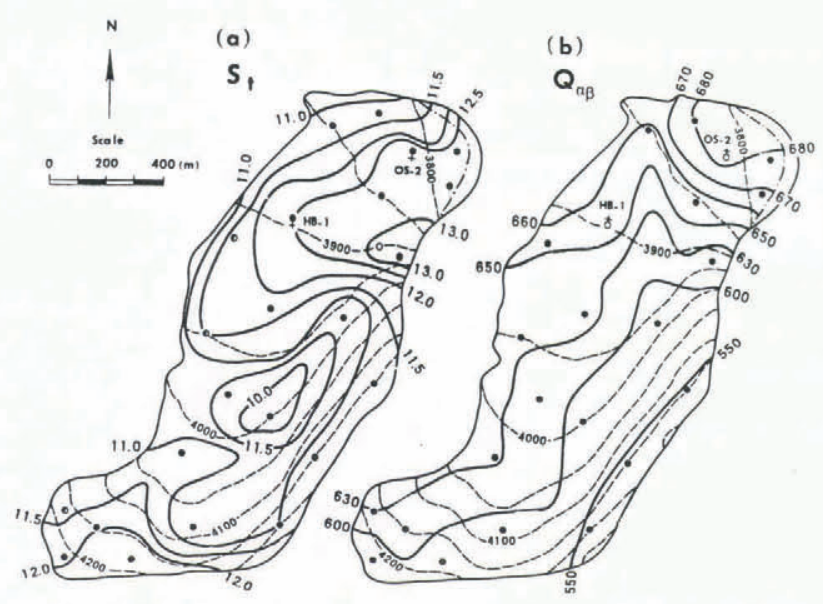

Fig.3. Distribution charts of mean daily value of insolation duration ( $S_{t}$, in hours), and of global radiation on the physical surface of the East-branch glacier $\left(Q_{\alpha \beta}\right.$, in Ly/day) in July 1983, in clear weather.

West Qiongtailan Glacier, Qieerganbulake Glacier), it can be said that the net radiation increases linearly with absorbed radiation. The following regression formulae were determined:

$$
B=0.8799 Q\left(1-A_{k}\right)-41.47 \text { (in Ly/day) }
$$

(for a whole mountain glacier in West China)

$$
B=1.0184 Q\left(1-A_{k}\right)-123.23 \text { (in Ly/day) }
$$

(for the glacierized region of Urumqi River)

Using the above formulae and observed data along the cross-section ablation atakes, the spatial distribution charts were plotted in Figure 4.

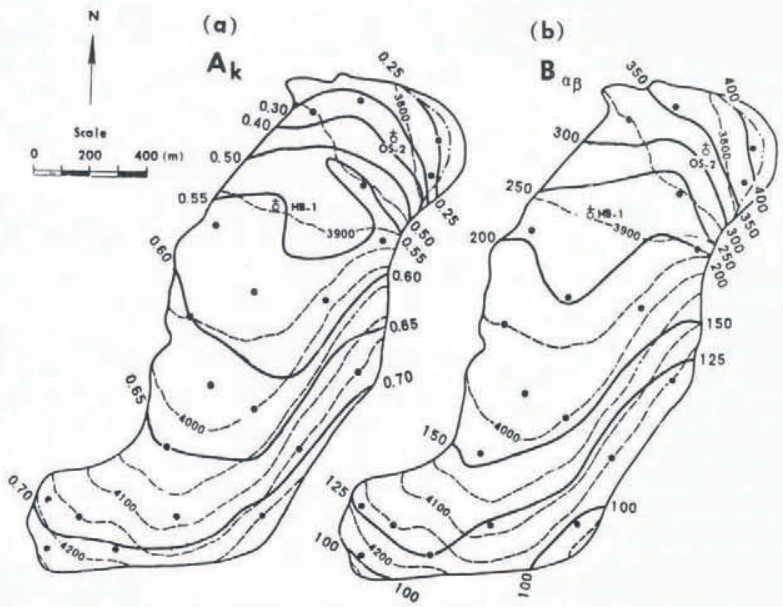

Fig.4. Distribution charts of mean monthly albedo $\left(A_{k}\right)$, and of mean daily radiation balance on the physical surface of the East-branch glacier (B $\alpha \beta$, in Ly/day) in July 1983, in clear and semi-clear weather.

\section{CONCLUSION}

It has been shown that mountain glaciers situated at various climatic regions and altitudes of West China have different snowline heights, development conditions and glacierized dimensions, due to variations in radiation and heat exchange processes. Calculations presented here show that the screening effect of the mountain and differences in heat balance are very important to the maintenance of glaciers in particular valleys, and explain why there are no glaciers in certain cirques or valleys at the same altitudes.

This work suggests methods which may be used to calculate the ablation and heat budget for the whole glacier, so that it can be applied to the study of the glacier climatology and glacier hydrology.

\section{ACKNOWLEDGEMENTS}

The research was supported by the Glaciological Division and Tianshan Glaciological Station. We are grateful to Professor Shi Yafeng for his guidance and valuable advice, to Zhang Huixing for his calculation of direction and angle of the slope of this region, and to Mrs Jin Zengmei for her preparation of illustrations. Part of this work was done under the Sino-Japanese glaciological project with $\mathrm{Mr}$ Tetsuo Ohata.

\section{REFERENCES}

Kou Youguan, Xie Weirong, Xiao Shu, Li Wenzhong 1982a The heat balance on glacier surface in China. Memoirs of Lanzhou Institute of Glaciology and Cryopedology, Academia Sinica 3: 91-101

Kou Youguan, Xie Weirong, Zhang Yongliang 1982b The potential of solar energy for melting ice and snow at high mountains in China. Memoirs of Lanzhou Institute of Glaciology and Cryopedology, Academia Sinica 3: 102-108

Shi Yafeng 1980 Some achievement on mountain glacier researches in China. Seppyo (Journal of the Japanese Society of Snow and Ice) 42(4): 215-228

Wang Zhonglong, Deng Yangxin, Zen Xiangyin 1982 The water-heat condition of the development of maritime glacier in Guxiang. Memoirs of Lanzhou Institute of Glaciology and Cryopedology, Academia Sinica 3: 82-91

Wendler D, Ishikawa H 1974 The effect of slope, exposure and moutain screening on the solar radiation of McCall Glacier, Alaska: a contribution to the International Hydrological Decade. Journal of Glaciology 13(68): 213-226 